University of Nebraska - Lincoln

DigitalCommons@University of Nebraska - Lincoln

Educational Psychology Papers and

Publications

Educational Psychology, Department of

$4-2010$

\title{
Being Bullied and Psychosocial Adjustment among Middle School Students in China
}

\author{
Yulan Cheng \\ Chinese Center for Disease Control and Prevention, zhgcyl2001@yahoo.com.cn \\ Ian Newman \\ University of Nebraska-Lincoln, inewman1@unl.edu \\ Ming Qu \\ Nebraska Department of Health \& Human Services, ming.qu@dhhs.ne.gov \\ Lazarous Mbulo \\ Nebraska Department of Health \& Human Services, lazarous.mbulo@hhss.ne.gov \\ Yan Chai \\ Chinese Center for Disease Control and Prevention, skyswallow2005@yahoo.com.cn \\ See next page for additional authors
}

Follow this and additional works at: https://digitalcommons.unl.edu/edpsychpapers

Part of the Educational Psychology Commons

Cheng, Yulan; Newman, Ian; Qu, Ming; Mbulo, Lazarous; Chai, Yan; Chen, Yan; and Shell, Duane F., "Being Bullied and Psychosocial Adjustment among Middle School Students in China" (2010). Educational Psychology Papers and Publications. 106.

https://digitalcommons.unl.edu/edpsychpapers/106

This Article is brought to you for free and open access by the Educational Psychology, Department of at DigitalCommons@University of Nebraska - Lincoln. It has been accepted for inclusion in Educational Psychology Papers and Publications by an authorized administrator of DigitalCommons@University of Nebraska - Lincoln. 


\section{Authors}

Yulan Cheng, lan Newman, Ming Qu, Lazarous Mbulo, Yan Chai, Yan Chen, and Duane F. Shell 
Published in Journal of School Health 80:4 (April 2010), pp. 193-199; doi: 10.1111/j.1746-1561.2009.00486.x

Copyright (C) 2010 American School Health Association; published by Wiley-Blackwell. Used by permission.

Submitted December 11, 2008; accepted October 13, 2009.

\title{
Being Bullied and Psychosocial Adjustment among Middle School Students in China
}

Yulan Cheng, MD, MPH - Associate Professor, National Institute for Health Education, Chinese Center for Disease Control \& Prevention, Room 604, 1 Qu 12 Lou, Anhua Xili, Beijing 100011, PR China; zhgcyl2001@ yahoo.com.cn

Ian M. Newman, PhD - Director, Nebraska Prevention Center for Alcohol and Drug Abuse, University of Nebraska-Lincoln, PO Box 880345, Lincoln, NE 68588-0345; inewman1@unl.edu

Ming Qu, PhD - Acting Administrator, Public Health Support Unit, Division of Public Health, Nebraska Department of Health \& Human Services, PO Box 95007, Lincoln, NE 68509-5007; ming.qu@dhhs.ne.gov

Lazarous Mbulo, PhD - Health Surveillance Specialist, Tobacco-Free Nebraska, Division of Health Promotion and Disease Prevention, Nebraska Department of Health \& Human Services, PO Box 95044, Lincoln, NE 68509-5044; lazarous.mbulo@hhss.ne.gov

Yan Chai, MPH - Research Assistant, National Institute for Health Education, Chinese Center for Disease Control and Prevention, Room 604, 1 Qu 12 Lou, Anhua Xili, Beijing 100011, PR China; skyswallow2005@yahoo.com.cn

Yan Chen, MPH - Research Assistant, National Institute for Health Education, Chinese Center for Disease Control and Prevention, Room 418, 1 Qu 12 Lou, Anhua Xili, Beijing 100011, PR China; chenyan.cy@126.com

Duane F. Shell, PhD - Associate Research Professor, Department of Educational Psychology, University of Nebraska-Lincoln, PO Box 880345, Lincoln, NE 68588-0345; dshell2@unl.edu

Corresponding author - Ian M. Newman

\begin{abstract}
Background: Using the Chinese version of the Global School-based Health Survey (GSHS), this article describes the prevalence of being bullied among a nationally representative sample of Chinese students in grades 6-10 and explores the relationships between being bullied and selected indicators of psychosocial adjustment.

Methods: A total of 9015 students in middle schools in Beijing, Hangzhou, Wuhan, and Urumqi completed the Chinese version of the GSHS. Researchers analyzed the results from 2 questions about the frequency and form of being bullied and 11 questions about psychosocial adjustment. Descriptive statistics and logistic regression were used in the analysis.

Results: About $25.7 \%$ of middle school students reported being bullied on 1 or more of the past 30 days. Rates of being bullied were similar for males and females, but the forms of being bullied were different. Being bullied was significantly lower in Beijing than in the other 3 cities. There were significant psychosocial differences between students who had been bullied and students who had not been bullied. Students who had been involved in a physical fight, often felt lonely, or had considered suicide in the past 30 days were more likely to report being bullied. Students who thought that other students in their school were often kind and helpful, who felt parents often understood their troubles, or who were taught in school how to handle stress were less likely to report being bullied.

Conclusions: Being bullied is not uncommon in Chinese middle schools. Chinese schools typically place great emphasis on academic achievement, perhaps at the expense of the social climate of the school. Results indicated schools could implement changes to the school climate to reduce the likelihood of students' being bullied.
\end{abstract}

Keywords: bullying, psychosocial, middle school, China 
$\mathrm{B}_{\mathrm{t}}^{\mathrm{u}}$ ullying among school-aged children is an international concern. ${ }^{1}$ Recent studies on school-aged children in the United States, ${ }^{2-6}$ England, ${ }^{7}$ South Africa, ${ }^{8}$ Korea, ${ }^{9,10}$ Japan,, ${ }^{11}$ Australia, ${ }^{12}$ Hong Kong, ${ }^{13}$ Germany, ${ }^{1}$ Norway, ${ }^{1}$ and Sweden ${ }^{1}$ suggest that bullying impacts the physical, emotional, and social health of the children involved. Bullying and being bullied are associated with poorer psychosocial adjustment. ${ }^{3}$ Children who are bullied demonstrate poorer social and emotional adjustment, greater difficulty in making friends, poorer relationships with classmates, and greater loneliness. ${ }^{3}$ Children who are bullied have more adjustment problems, including internalizing disorders, externalizing disorders, social difficulties, physical health problems, and suicide ideation. ${ }^{14}$ The victims of bullying have few or no close friends at school and are socially isolated. ${ }^{15}$ Victimized children tend to have increased school absenteeism and avoid school more as the victimization increases. ${ }^{15,16}$ Research in Australia, Finland, and Norway suggests that these psychosocial challenges may persist into later adolescence and adulthood.,14 Bullying is a problem that influences individuals, peer groups, families, schools, and communities and, as such, is a significant international public health challenge.

Olweus ${ }^{17}$ describes bullying as aggressive behavior or intentional harm-doing that is carried out repeatedly over time in an interpersonal relationship characterized by an imbalance of power. Bullying behavior can be physical (hitting, pushing, and kicking), verbal (namecalling, provoking, making threats, and spreading rumors), and it can include other behaviors, such as making faces and creating social exclusion. ${ }^{1}$ Direct physical aggression is more common among boys and includes being hit, kicked, pushed, shoved around, or locked indoors. ${ }^{18,19}$ Indirect bullying, such as name-calling, teasing, rumors, rejection, and the taking of personal belongings is more common among girls. Most research indicates that boys are more likely to be bullied than girls. $3,8,9,12,17-24$

Research over the past 15 years has shown that bullying is prevalent across countries ${ }^{1}$ with considerable variability reported among countries. The percentage of students who reported being bullied at least once during the current school term ranged from a low of $6-20 \%$ to a high of $67 \% .1,4,8,9,11,19-21,25,26$

Eslea et al. ${ }^{26}$ summarized the survey of 4726 primary and junior middle school students in rural and urban areas of Shandong province using a Chinese version of the Olweus Bully/Victim Questionnaire and found 2\% were bullies, $13.3 \%$ were victims, and $1.5 \%$ were both bully and victim. Chen and Yue ${ }^{27}$ used the Chinese version of the Olweus survey with 3332 primary and junior middle school students in Tianjing and found $21.3 \%$ of males and $18.7 \%$ of females reported being victims of bullying, and $7.9 \%$ of males and $1.5 \%$ of females were bullies. Hazemba et al., ${ }^{23}$ using the GSHS data for Beijing, found $20 \%$ of Beijing students reported being bullied.

Based on the results of the Chinese version of the GSHS, this article describes the prevalence of bullying and explores the relationships between bullying and selected indicators of psychosocial adjustment, using a nationally representative sample of Chinese students in grades 6-10.

\section{Method}

\section{Subjects}

The sample represented students in 7th through 10th grades in 100 middle schools in four cities representing China's different regions: Beijing, Hangzhou, Wuhan, and Urumqi; that is, China's capital, an eastern, a central, and a western city.

The GSHS used the same 2-stage cluster sample selection process as used in the US Youth Risk Behavior Survey. In the first stage, a list of all the middle schools in each city, with grades that included students aged 13-15, was submitted to US Centers for Disease Control and Prevention (USCDC). USCDC selected 25 schools from each city with probability proportional to school enrollment. The second stage involved randomly selecting classrooms from each participating school. All classrooms in each school were sampled and all students in the sampled classrooms were eligible to participate. The selected sample included 9173 students. A total of 9015 $(98.28 \%)$ students completed the questionnaires and $100 \%$ of the selected schools participated (Table 1).

\section{The Instrument}

The GSHS was developed in 2001 by the World Health Organization, in collaboration with UNAIDS, United Nations Educational, Scientific and Cultural Organization (UNESCO), The United Nations Children's Fund (UNICEF), and the USCDC and conducted primarily among students 13-15 years old. The GSHS aims to measure behaviors related to the leading causes of mortality and morbidity. The China version used the GSHS core questionnaire modules, core-expanded questions, and country-specific questions to form a self-administered questionnaire that could be answered within 1 regular class period. The Chinese GSHS was pilot tested in Beijing in 2002. Translation and back-translation and revisions were overseen by the China Center for Disease Control and Prevention (CCDC) in cooperation with the USCDC. 
Table I. The Sample: Demographic Characteristics and Percent of Students Bullied

\begin{tabular}{lrrc}
\hline Characteristics & $\mathrm{N}^{*}$ & $\%^{\dagger}$ & $\begin{array}{c}\text { \% Reported Bullied } \\
(95 \% \text { Confidence Interval })\end{array}$ \\
\hline Total & 9015 & 100 & $25.7(24.0-27.5)$ \\
$\quad$ Region & & & \\
Beijing & 2348 & 51.3 & $20.0(17.1-23.2)$ \\
Hangzhou & 1802 & 17.7 & $32.0(29.8-34.4)$ \\
Wuhan & 1947 & 21.7 & $32.0(29.4-34.7)$ \\
Urumqi & 2918 & 9.3 & $31.6(28.6-34.7)$ \\
Sex & & & \\
Male & 4356 & 48.2 & $27.4(25.4-29.6)$ \\
Female & 4537 & 50.5 & $23.8(21.8-25.9)$ \\
Missing & 122 & 1.3 & \\
Age & & & \\
I2 or younger & 1188 & 13.6 & $24.6(21.5-28.0)$ \\
I3 & 2639 & 28.6 & $26.2(23.1-29.5)$ \\
I4 & 2832 & 31.6 & $27.5(24.8-30.4)$ \\
I5 or older & 2264 & 25.2 & $23.4(20.3-26.9)$ \\
Missing & 92 & 1.0 & \\
Grade & & & \\
7th & & & \\
8th & & & \\
9th and I0th & 3222 & 34.6 & $24.5(21.8-27.4)$ \\
Missing & 152 & 1.5 & \\
\hline * Unweighted N. & & & \\
† Weighted percentage. & & & \\
& & &
\end{tabular}

The Chinese version contained 83 multiple-choice questions about alcohol and other drug use, dietary behaviors, hygiene, mental health, physical activity, protective factors, tobacco use, violence and unintentional injuries, school and parental influences, and Severe Acute Respiratory Syndrome (SARS). ${ }^{28}$

Participants reported their age, gender, and grade. The questionnaire was administered in classes by specially trained data collectors. Classroom teachers were not involved in the data collection. Survey procedures were designed to protect students' privacy by allowing for anonymous and voluntary participation.

Questions about being bullied were preceded with the following explanation (translated here into English):

The next 2 questions ask about being bullied. Bullying occurs when a student or group of students say or do bad and unpleasant things to another student. It is also bullying when a student is teased a lot in an unpleasant way or when a student is left out of things on purpose. It is not bullying when 2 students of about the same strength or power argue or fight, or when teasing is done in a friendly and fun way.

Being bullied was assessed by the question "During the past 30 days, on how many days were you bullied?"
English translations of the response categories were "0 days," " 1 or 2 days," " 3 to 5 days," "6 to 9 days," " 10 to 19 days," "20 to 29 days," and "all 30 days." The form of bullying was assessed by the question, "During the past 30 days, how were you bullied most often?" Response categories were "I was not bullied during the past 30 days," "I was hit, kicked, pushed, shoved around, or locked indoors," "I was made fun of because of my race or color," "I was made fun of because of my religion," "I was made fun of with sexual jokes, comments, or gestures," "I was left out of activities on purpose or completely ignored," "I was made fun of because of how my body or face looks," "I was bullied in some other way."

Psychosocial adjustment was assessed by the following survey questions: "During the past 12 months, how often have you felt lonely?"; "During the past 12 months, how often have you been so worried about something that you could not sleep at night?"; "During the past 12 months, did you ever feel so sad or hopeless almost every day for 2 weeks or more in a row that you stopped doing your usual activities?"; "During the past 12 months, did you ever seriously consider attempting suicide?"; "During the past 12 months, did you make a plan about how you would attempt suicide?"; "During the past 30 days, how many days did you miss classes or school without permission?"; "During the past 12 months, how many times were you in a physical fight?"; "How many close friends do you have?"; "During the past 30 days, how often were most of the students in your school kind and helpful?"; "During the past 30 days, how often did your parents or guardians understand your problems and worries?"; "During the last school year, were you taught in any of your classes how to handle stress in healthy ways?" Questions about loneliness, worry, students being kind and helpful, and parents' understanding were answered "never/rarely/ sometimes" or "most of the time/always." Other questions were coded as either "no" or "yes."

\section{Procedures}

The National Institute for Health Education/CCDC managed this project in cooperation with the 4 provincial CDCs containing the cities. Survey procedures were designed to protect students' privacy. Participation was anonymous and voluntary. Permission to carry out the survey was obtained from the CCDC, and the departments of education and health in each participating city and from the administration of each selected school. Parental/guardian forms were used to obtain permission for participation. All data processing (scanning, cleaning, editing, and weighting) was conducted at USCDC.

A weighting factor was applied to each student record to adjust for no response and for the varying prob- 
Table 2. Forms of Being Bullied

\begin{tabular}{|c|c|c|c|c|c|c|c|c|c|}
\hline \multirow[b]{2}{*}{ Forms of Bullying } & \multicolumn{2}{|c|}{ Total } & \multicolumn{2}{|c|}{ Male } & \multicolumn{2}{|c|}{ Female } & \multirow[b]{2}{*}{$x^{2}$} & \multirow[b]{2}{*}{ Odds Ratio } & \multirow{2}{*}{$\begin{array}{c}\text { Confidence } \\
\text { Interval }\end{array}$} \\
\hline & $\mathrm{N}$ & $\%^{\dagger}$ & $\mathrm{N}$ & $\% \dagger$ & $\mathrm{N}$ & $\%^{\dagger}$ & & & \\
\hline Hit, kicked, pushed, shoved around, or locked indoors & 461 & 19.7 & 315 & 26.4 & 146 & 12.7 & $70.47^{*}$ & 2.73 & $2.20-3.38$ \\
\hline Made fun of because of religion & 24 & 1.0 & 12 & 1.0 & 12 & 1.0 & 0.0064 & 1.49 & $0.48-4.67$ \\
\hline Made fun of with sexual jokes, comments, or gestures & 246 & 10.5 & 126 & 10.6 & 120 & 10.4 & 0.0184 & 1.39 & $0.95-2.02$ \\
\hline Left out of activities on purpose or completely ignored & 149 & 6.4 & 67 & 5.6 & 82 & 7.1 & 2.1743 & 0.87 & $0.56-1.36$ \\
\hline Bullied in some other way & 1021 & 43.6 & 506 & 42.5 & 515 & 44.7 & 1.1333 & 1.079 & $0.91-1.28$ \\
\hline Total & 2344 & 100 & 1191 & 100 & 1153 & 100 & & & \\
\hline
\end{tabular}

${ }^{*} \mathrm{p}<.001$

tWeighted percentage.

abilities of selection. (1) Weights were scaled so that the weighted count of students was equal to the total sample size; and (2) the weighted proportions of students matched national populations. The weight used for estimation is given by the following formula: $\mathrm{W}=\mathrm{W} 1 \times \mathrm{W} 2$ $\times \mathrm{f} 1 \times \mathrm{f} 2 \times \mathrm{f} 3 \times \mathrm{f} 4$; where $\mathrm{W} 1=$ the inverse of the probability of selecting the school, W2 $=$ the inverse of the probability of selecting the classroom within the school, $\mathrm{fl}=\mathrm{a}$ school-level nonresponse adjustment factor calculated by school size category (small, medium, large), f2 $=$ a class-level nonresponse adjustment factor calculated for each school, $\mathrm{f} 3=$ a student-level nonresponse adjustment factor calculated by class, and $\mathrm{f} 4=$ a poststratification adjustment factor calculated by grade.

\section{Data Analysis}

SUDAAN SAS9-Callable 9.0.1, ${ }^{29}$ was used to obtain percentage distributions and confidence intervals (CIs). All CIs are shown at the $95 \%$ level. Logistic regression was used to examine factors that may predict bullying. These included location, loneliness, anxiety, sadness, attempting suicide, planning suicide, missing school, being in a physical fight, perceptions of others about school, having close friends, parental understanding, and having been taught to handle stress.

\section{Results}

\section{Prevalence of Being Bullied}

In this weighted sample, $25.7 \%$ of the students reported being bullied on 1 or more of the past 30 days; $58.7 \%$ on 1 or 2 days; $18.1 \%$ on 3 to 5 days; $7.6 \%$ on 6 to 9 days, $5.2 \%$ on 10 to 19 days; $2.5 \%$ on 20 to 29 days, and $7.9 \%$ on all 30 days. Based on CIs, significantly fewer children in Beijing reported being bullied, compared to the other cities. Bullying rates by sex, age, and grade suggested no notable differences (Table 1).

\section{Forms of Being Bullied}

As Table 2 shows, the types of bullying most frequently reported were (1) "hit, kicked, pushed, shoved around, or locked indoors," (2) "made fun of because of how body or face looks," and (3) "made fun of with sexual jokes, comments, or gestures." The largest percentage of the 2327 students who reported being bullied during the past 30 days answered they were "bullied some other way." We will address this in the Discussion section. Boys were significantly more likely to report being "hit, kicked, pushed, shoved around, or locked indoors." Girls were significantly more likely to report being "made fun of because of how body or face looks."

\section{Consequences of Being Bullied}

Logistic regression indicated that the odds of being bullied were significantly higher if a student reported "often" or "always" feeling lonely, considering suicide in the past 30 days, being in a physical fight, or missing school without permission. Students who "often" or "always" felt fellow students were kind and helpful, felt parents understood their troubles, or had been taught how to handle stress were considerably less likely to report being bullied (Table 3).

\section{Discussion}

Bullying is not uncommon among middle school students in China. More than $25 \%$ of the students sampled in this study reported being bullied in the past 30 days. Among those who reported being bullied, more than $10 \%$ reported being bullied on more than 20 days of the past 30 days. These self-reported rates are in the lower range of rates of being bullied among students of this age in a variety of other countries,,$^{2,4-6,8,9,12,19-22,25}$ higher than the $13.3 \%$ reported in Eslea et al. ${ }^{26}$ for China and nearer the $20 \%$ reported by Chen and Yue ${ }^{27}$ for Tianjing 
Table 3. Consequences of Being Bullied

\begin{tabular}{|c|c|c|c|c|c|c|}
\hline Independent Variables & Total $\%^{\dagger}$ & Bullied \% ${ }^{\dagger}$ & Not Bullied \% ${ }^{\dagger}$ & $x^{2}$ & Odds Ratio & Confidence Interval \\
\hline \multicolumn{7}{|l|}{ Region $(\mathrm{N}=9015)$} \\
\hline Beijing & 51.9 & 20.0 & 80.0 & & I & \\
\hline Wuhan & 21.2 & 32.0 & 68.0 & 21.1 & 1.62 & $1.32-2.00$ \\
\hline Urumqi & 9.1 & 31.5 & 68.5 & 20.4 & 1.68 & $1.34-2.10$ \\
\hline \multicolumn{7}{|l|}{ Feel lonely $(\mathrm{N}=8976)$} \\
\hline \multicolumn{7}{|l|}{ Being worried $(N=897 \mathrm{I})$} \\
\hline Often/always & 25.6 & 7.3 & 3.1 & 3.13 & $\mathrm{I} .322$ & $0.97-1.80$ \\
\hline Never/rarely/sometimes & 74.1 & 92.7 & 96.9 & & & \\
\hline \multicolumn{7}{|l|}{ Feel sad/hopeless $(N=8920)$} \\
\hline Often/always & 25.6 & 25.8 & 16.7 & 2.93 & 1.130 & $0.98-1.30$ \\
\hline \multicolumn{7}{|c|}{ Ever consider suicide $(\mathrm{N}=888 \mathrm{I})$} \\
\hline \multicolumn{7}{|c|}{ Ever make suicide plan $(\mathrm{N}=890 \mathrm{I})$} \\
\hline Often/always & 25.7 & 13.0 & 5.4 & 2.0 & 1.233 & $0.93-1.64$ \\
\hline Never/rarely/sometimes & 74.4 & 87.0 & 94.7 & & & \\
\hline \multicolumn{7}{|c|}{ Being in a physical fight $(\mathrm{N}=8990)$} \\
\hline Often/always & 25.7 & 27.0 & 14.0 & $40.7^{*}$ & $\mathrm{I} .774$ & $1.49-2.12$ \\
\hline Never/rarely/sometimes & 74.3 & 73.0 & 86.0 & & & \\
\hline \multicolumn{7}{|c|}{ Miss school no permission $(\mathrm{N}=8902)$} \\
\hline Often/always & 25.6 & 8.4 & 4.3 & $4.87^{*}$ & 1.314 & $1.03-1.68$ \\
\hline Never/rarely/sometimes & 74.4 & 91.6 & 95.7 & & & \\
\hline \multicolumn{7}{|l|}{ Have close friend $(\mathrm{N}=8935)$} \\
\hline Often/always & 25.6 & 36.1 & 55.6 & 3.10 & 1.243 & $0.98-1.58$ \\
\hline Often/always & 25.6 & 51.3 & 59.9 & 1.0 & 0.932 & $0.8 \mathrm{I}-\mathrm{I} .07$ \\
\hline Never/rarely/sometimes & 74.4 & 48.7 & 40.1 & & & \\
\hline
\end{tabular}

${ }^{*} \mathrm{p}<.001$.

tWeighted percentage.

and Hazemba et al. ${ }^{23}$ for Beijing. As to why rates of being bullied in China would be lower than in other countries, possible explanations are that there is less bullying, Chinese students do not count certain forms of harassment as bullying, Chinese students hesitate to report being bullied, or that the wording of the survey missed some culturally nuanced understanding of bullying.

The rates of being bullied among males and females were similar. Zhang et al. $^{24}$ and Chen and Yue ${ }^{27}$ also found little gender difference in the prevalence of being bullied.

The forms of bullying did differ by gender. Males were more likely to be victims of direct physical bullying, involving kicking, pushing, and hitting, while fe- males were more likely to be bullied psychologically, involving exclusion and rumors. These gender patterns are similar to those reported by Murray-Close and Crick ${ }^{18}$ as involving physical aggression for boys and relational aggression for girls. Similarly, Zhang et al. ${ }^{24}$ found direct physical bullying more common among boys, indirect bullying more common among girls, but no gender difference in verbal bullying. Chen and $\mathrm{Yue}^{27}$ found verbal bullying the most frequent type among junior middle school girls and physical bullying more prevalent among boys than girls of all ages.

No significant differences among age and grades were observed in this sample. Others have reported the highest levels of bullying and victimization occur- 
ring among elementary school students with a decline through secondary school. ${ }^{21,27}$ This study included only middle school students, precluding any meaningful age/grade comparison. Exactly, how bullying rates compare among students in elementary and secondary schools in China remains an important question.

The different rates of being bullied between students in Beijing and in the other 3 cities were intriguing. In China, over the past 20 years, schools have placed great emphasis on academic performance at the expense of student services. Consequently, many students lack problem-solving and conflict resolution skills. The Fourth Conference of the Eighth National People's Congress held in 1996 noted the need to improve students' moral conduct and increase their innovative capabilities. Since then, more emphasis has been placed on developing the whole student and creating school environments with social climates that support academic achievement. Issues of mental health, interpersonal relationships, and parental support have taken on new importance. The data presented here were gathered in 2003 and might suggest that the schools in Beijing may have progressed further in this regard than those in the other 3 cities. For example, students in the Beijing schools who thought that most of the students in their school were kind and helpful most of the time or always, were higher than $(57.9 \%)$ than the percent in the other 3 cities: Urumqi, 49.5\%; Hangzhou, 44.4\%; and Wuhan, 36.3\% ( $p<.01)$.

Findings from this study show a consistent relation between being bullied and a number of indicators of psychosocial adjustment. This study demonstrated that being bullied does interact with psychosocial adjustment problems. Being bullied has been suggested as a strong risk factor for the later development of psychosocial adjustment problems. Students with psychosocial adjustment problems - such as loneliness, depression, or anxiety, lower self-esteem, few or no close friends at school, social isolation, and lack of a support network - may be more vulnerable to being bullied by other children. ${ }^{25}$

From this research, a number of factors can be described as protective for being bullied. Students who reported that most of the students in their school were kind and helpful most of the time or always, had parents or guardians who most of the time or always understood their problems and worries, who had close friends, and who had received education on how to handle stress in healthy ways were less likely to be bullied than those who had not. This suggests that a supportive social network in school and at home contributes significantly to lowering the risks that a student will be bullied. Such an outcome is clearly in support of the objective of schools. There is a need to more widely confirm these results to support the recommendations of the
Eighth National People's Congress. Unfortunately, experience with this issue in the United States suggests that many policy makers believe academic achievement can only be gained when it becomes the single focus of the schools, at the expense of concerns that involve the whole student and the school social environment.

\section{Limitations}

In considering the results presented here, a number of important limitations should be noted. The GSHS is a broadly focused survey of health behaviors of middle school-age students. As such, in-depth information on bullying was unavailable. Comparisons with other bullying studies in China that used the Olweus Bully/Victim Questionnaire are made cautiously. The collected data are cross-sectional and do not support the exploration of causal pathways. As with all student surveys, these results are based on self-reporting measures. These can be affected by the methods and organization of data collection and whether the students have an accurate understanding of the questions asked.

Translating the GSHS raises the question whether corresponding words in English and Chinese had identical meanings. Smith et al. ${ }^{30}$ have shown that definitions of bullying can be subtle and culturally specific. The GSHS preceded the questions on bullying with a paragraph describing specific actions that students should consider as bullying. Smith et al..$^{30}$ found that students in China applied the Chinese word qifu (the word used in the GSHS bullying questions) to $94 \%$ of physical bullying cartoons, $85 \%$ of direct and indirect verbal bullying cartoons, and $68 \%$ of social exclusion cartoons. Nevertheless, $43.6 \%$ of the students in this study selected the answer option "bullied some other way." This suggests certain incompleteness in the options presented by the GSHS for the question "How were you bullied most often?" Further study is needed into what specific behaviors these Chinese students considered to be bullying "in some other way."

Bullying is not a static concept. For example, the rapid diffusion of cell phones provides a previously unanticipated means for bullying. Maintaining currency with the potential means for bullying will require careful attention to the involvement of students in the development of any future bullying questionnaires.

\section{Implications for School Health}

This study is an examination of the prevalence and the characteristics of being bullied among a nationally representative sample of Chinese middle school students using the 2003 GSHS data. These results provide a basis for planning future research and suggest initial strat- 
egies school leaders can pursue to decrease the prevalence of bullying.

If a reduction in bullying is to be achieved, a comprehensive approach will be needed, involving changes in school and classroom climate, increased teacher-parent involvement, development of social norms and rules discouraging bullying, and making available psychological services to emotionally at-risk students. An appropriate comprehensive framework for bullying prevention is the World Health Organization Health Promoting School framework. ${ }^{31}$ All parties, that is, school staff, students, and parents, as well as organizations connected to the school's community, should be involved in cooperative efforts to improve the family, school, and community climate to prevent and diminish school bullying.

Human Subjects Approval Statement: This study was approved by the National Institute for Health Education, China CDC Institutional Review Board.

\section{References}

1. Nansel TR, Craig W, Overpeck MD, Saluja G, Ruan WJ. The Health Behaviour in School-Aged Children Bullying Analyses Working Group. Cross-national consistency in the relationship between bullying behaviors and psychosocial adjustment. Arch Pediatr Adolesc Med. 2004; 158:730-736.

2. Kim YS, Leventhal BL, Yun-Joo Koh, Hubbard A, Boyce WT. School bullying and youth violence-Causes or consequences of psychopathologic behavior? Arch Gen Psychiatry. 2006; 63:1035-1041.

3. Nansel TR, Overpeck M, Pilla RS, Ruan WJ, Simons-Morton B, Scheidt P. Bullying behaviors among US youth: Prevalence and association with psychosocial adjustment. JAMA. 2001; 285:2094-2100.

4. Nansel TR, Overpeck MD, Haynie DL, Ruan WJ, Scheidt PC. Relationships between bullying and violence among US youth. Arch Pediatr Adolesc Med. 2003; 157:348-353.

5. Glew GM, Fan MY, Katon W, Rivara FP, Kernic MA. Bullying, psychosocial adjustment, and academic performance in elementary school. Arch Pediatr Adolesc Med. 2005; 159:1026-1031.

6. Juvonen J, Graham S, Schuster MA. Bullying among young adolescents: The strong, the weak, and the troubled. Pediatrics. 2003; 112:1231-1237.

7. Arseneault L, Milne BJ, Taylor A, et al. Being bullied as an environmentally mediated contributing factor to children's internalizing problems - A study of twins discordant for victimization. Arch Pediatr Adolesc Med. 2008; 162(2):145-150.

8. Liang H, Flisher AJ, Lombard CJ. Bullying, violence, and risk behavior in South African school students. Child Abuse Negl. 2007; 31(2):161-171.

9. Kim YS, Koh YJ, Leventhal BL. Prevalence of school bullying in Korean middle school students. Arch Pediatr Adolesc Med. 2004; 158:737-741.

10. Kim YS, Koh YJ, Leventhal B. School bullying and suicidal risk in Korean middle school students. Pediatrics. 2005; 115:357-363.

11. Murray-Harvey R, Slee PT. Australian and Japanese school students' experiences of school bullying and victimization: Associations with stress, support and school belonging. Int J Violence Sch. 2006; 2:33-50.
12. Delfabbro P, Winefield T, Trainor S, et al. Peer and teacher bullying/victimization of South Australian secondary school students: Prevalence and psychosocial profiles. Br J Educ Psychol. 2006; 76:71-90.

13. Wong DSW. School bullying and tackling strategies in Hong Kong. Int J Offender Ther Comp Criminol. 2004; 48(5):537-553.

14. Arseneault L, Walsh E, Trzesniewski K, Newcombe R, Caspi A, Moffitt TE. Bullying victimization uniquely contributes to adjustment problems in young children: A nationally representative cohort study. Pediatrics. 2006; 118:130-138.

15. Blazer C. Literature Review on Bullying. Available at: $\underline{\mathrm{http}: / / \mathrm{drs} .}$ dadeschools.net/Reports/Bullying.pdf Accessed January 13, 2010.

16. Vreeman RC, Carroll AE. A systematic review of school-based interventions to prevent bullying. Arch Pediatr Adolesc Med. 2007; 161(1):78-88.

17. Olweus D. Annotation: bullying at school: Basic facts and effects of school based intervention programs. J Child Psychol Psychiatry 1994:35:1171-1190.

18. Murray-Close D, Crick NR. Mutual antipathy involvement: Gender and associations with aggression and victimization. School Psych Rev. 2006; 35(3):472-492.

19. Miguel-Baquilod M. Philippines Country Report, 2003. Available at: http://0-www.cdc.gov.library.unl.edu/gshs/countries/westpacific/philippines.htm Accessed January 13, 2010.

20. Qaseer BMA, Atoum HA, Batarseh S, Al Jawhari NM. Jordan Country Report, 2004. Available at: http://0-www.cdc.gov.library. unl.edu/gshs/countries/eastmediter/jordan.htm Accessed January 13, 2010.

21. Twa-Twa JM, Oketcho S. Uganda Country Report, 2003. Available at: http://0-www.cdc.gov.library.unl.edu/gshs/countries/africa/ uganda.htm Accessed January 13, 2010.

22. Dake JA, Price JH, Telljohann SK. The nature and extent of bullying at school. J Sch Health. 2003; 73(5):173-180.

23. Hazemba A, Siziya S, Muula AS, Rudatsikira E. Prevalence and correlates of being bullied among in-school adolescents in Beijing: Results from the 2003 Beijing Global School-based Health Survey. Ann Gen Psychiatry. 2008; 7:6. Available at: http://www.annals-generalpsychiatry.com/content/7/1/6 Accessed January 13, 2010.

24. Zhang W, Gu C, Wang M, Wang Y. Gender differences in bullying and victimization among primary and junior middle school pupils [in Chinese]. Chinese Journal of Psychological Science. 2000; 23:435-439.

25. World Health Organization, USCDC, Ministry of Health of Zambia, Ministry of Education of Zambia. Zambia Country Report, 2004. Available at: http://0-www.cdc.gov.library.unl.edu/gshs/ countries/africa/zambia.htm Accessed January 13, 2010.

26. Eslea M, Menesini E, Morita Y, et al. Friendship and loneliness among bullies and victims: Data from seven countries. Aggress Behav. 2003; 30:71-83.

27. Chen SP, Yue GA. Survey on bullying behavior of primary school and middle school students [in Chinese]. Sci Mental Health. 2002; 25(3):355-356.

28. US Centers for Disease Control and Prevention. Global Schoolbased Health Survey: China Fact Sheet. Available at: http://0www.cdc.gov.library.unl.edu/gshs/countries/westpacific/china. htm Accessed January 13, 2010.

29. RTI International. About SUDAAN. Available at: http://www.rti. org/sudaan/index.cfm Accessed January 13, 2010.

30. Smith PK, Cowie H, Olafsson RF, Liefooghe APD. Definitions of bullying: A comparison of terms used, and age and gender differences, in a fourteen-country international comparison. Child Dev. 2002; 73(4):1119-1133.

31. World Health Organization. Regional Guidelines: Development of Health-Promoting Schools-A Framework for Action. Health Promoting Schools Series, Vol. 5. Manila, the Philippines: WHO, Western Pacific Regional Office; 1996. 